\title{
INVESTIGATION OF THE NATURE AND CAUSE OF THE DAMAGE TO PLANT TISSUE RESULTING FROM THE FEEDING OF CAPSID BUGS.
}

\author{
By KENNETH M. SMITH, A.R.C.S., D.I.C. \\ (Adviser in Agricultural Entomology, Manchester University.) \\ (With 1 Plate and 5 text-figures.)
}

Tris piece of work was suggested by Mr J. C. F. Fryer, entomologist to the Ministry of Agriculture and was carried out at the Royal College of Science, S. Kensington, under Prof. H. Maxwell Lefroy.

I wish to acknowledge my indebtedness to Prof. Blackman and Dr S. G. Paine, of the Imperial College of Science and Technology, for much valuable assistance and advice.

The object of this investigation was to discover the causes of the damage to plants and especially to apple trees from the feeding of Capsid bugs. There are many species of Capsids which normally feed on the fruit and leaves of apple trees in this country, those which have attracted most attention being the following: Plesiocoris rugicollis, Atractotomus mali, Orthotylus marginalis and Psallus ambiguus; only the first-named causes any damage to the fruit and foliage (Fryer(1), Petherbridge and Husain(2) and others). Lygus pratensis also is found by Collinge(3), to cause damage to the apple fruit itself by depositing its eggs in the lenticels, but not by sucking the juices. The problem to be solved is, then, as follows. There are four species of Capsid bugs, mostly closely allied, all feeding on apple fruit and foliage and feeding by the same process, i.e. by inserting their mouth-parts into the tissue and sucking the sap, yet only one of them, Plesiocoris rugicollis, causes any damage.

P. rugicollis hatches out in May, and the young Capsids immediately begin to feed voraciously, picking out the young shoots which soon become covered with spots and patches of dead cells; this has the effect of keeping back the shoots and young leaves to a very large extent, and in some cases causes the death of the whole shoot. When the young 
apples begin to form, the Capsids transfer their attention to these, which in their turn become rapidly covered with red spots, each spot, of course, marking the point of insertion of the stylets. Thus far the injury to the apple appears identical with that of the leaf, but after a short time the apple becomes cracked, a corky layer is formed, and a very distorted fruit results; in many cases the badly attacked apple ceases to grow and falls off. This is in marked contrast to the other three species mentioned above which feed in a similar manner and yet produce no ill effects whatever. The question then arises, what is there about this particular species in contrast with the others, that the sucking action should be followed by so lethal an effect upon the tissues of the foliage and fruit.

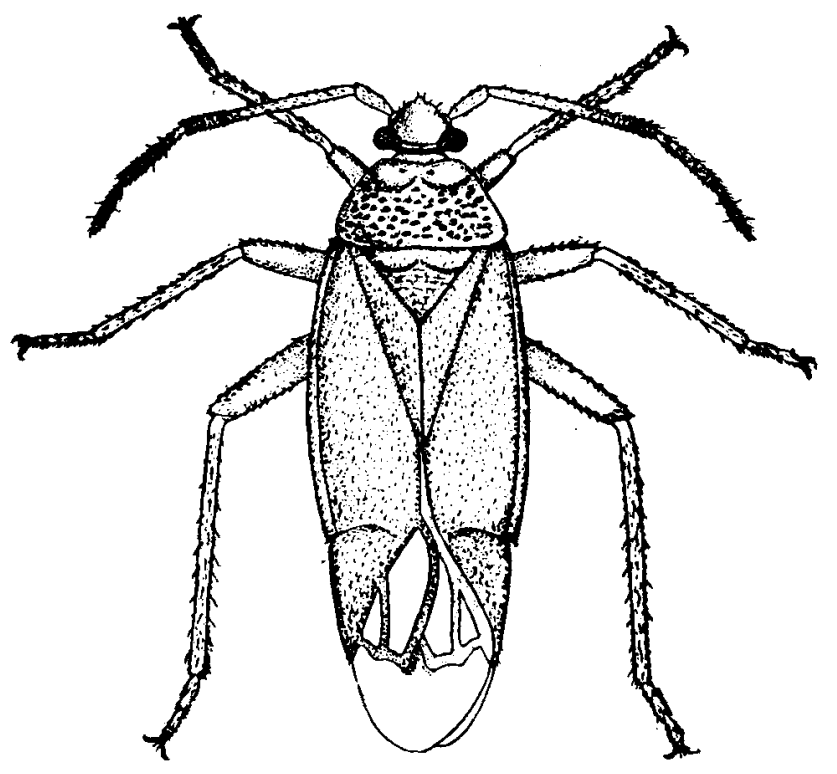

Fig. 1. Adult specimen of Plesiocoris rugicollis. After Petherbridge and Husain.

When this bug has sucked some of the sap, which it does by pushing its sharp stylets into the tissue and drawing up the liquid by means of a powerful pump situated in the head, at the same time injecting saliva into the wound (Awati(4)), the stylets are withdrawn and inserted elsewhere, meanwhile a drop of fluid gathers at the first puncture gradually getting larger as the cells are killed and yield up their contents. When this drop has dried up, the cells underlying it are all killed leaving a large discoloured patch which may eontinue to spread slightly especially if in the neighbourhood of a vein. 
In the case of the apple fruit these dead cells present a dark red or brown appearance owing to the formation of a tannin which gives a black coloration with ferrous sulphate. Microtome sections of portions of apple leaf injured by $P$. rugicollis show a mass of dead cells filled with a red granular material, the epidermis dying after the mesophyll, this confirms Petherbridge and Husain (2). When $P$. rugicollis feeds on Willow a clear space is produced round each puncture so that if damaged by several punctures the leaf becomes transparent and dies. Sections of such a leaf show that the cells are killed and filled with a clear substance very similar in appearance to that found in the cells of the apple, so that the reaction appears identical with that produced in the apple, with the exception of the colour reaction. The production of the red-brown pigment is merely a death phenomenon of the apple cells and is no special reaction to the Capsid; apple leaves if held in chloroform vapour produce the same red pigment.

We come now to consider the possible explanations of this damage. These seem to be three:

Firstly, a purely mechanical injury caused by the laceration of the tissues by the stylets in process of sucking.

Secondly, the possibility of the bug acting as a "carrier" of bacteria and injecting them into the plant along with the salivary juices and so setting up a pathological state. An interesting parallel to this is found in the case of the Beet Leaf hopper which carries the germs of beet curly top (Stahl and Carsner(5)).

Thirdly, the injection of some secretion, either from the salivary glands, which is the more probable, or a regurgitation from the stomach which has a virulent toxic effect on the tissue. These three theories seem to cover the only possible explanations of the damage. As has been mentioned already, the formation of the red brown pigment is a death phenomenon of the apple and it is possible by means of laceration with a sterile needle to produce a small brown spot similar in appearance to that produced by the Capsid but not approaching it in extent of the injury. The following attempts were made with sterile needles of varying fineness to reproduce the injury caused by the bugs.

(1) Scratch on the surface of the leaf with a dry sterile needle.

(2) Puncture with dry sterile needle.

(3) Scratch through sterile water.

(4) Puncture through sterile water.

(5) Puncture with dry needle not penetrating the leaf.

In each case only cells actually lacerated by the needles were killed, 
the injury did not spread and the leaves were not put back in their development.

If it is assumed that the injury is due to the mechanical laceration of the cells and their consequent loss of sap by the stylets of the bug, then the question arises, why do not the other species of apple feeding bugs produce the same effect? as the methods of feeding, and the mandibles and maxillary stylets are precisely the same in each case.

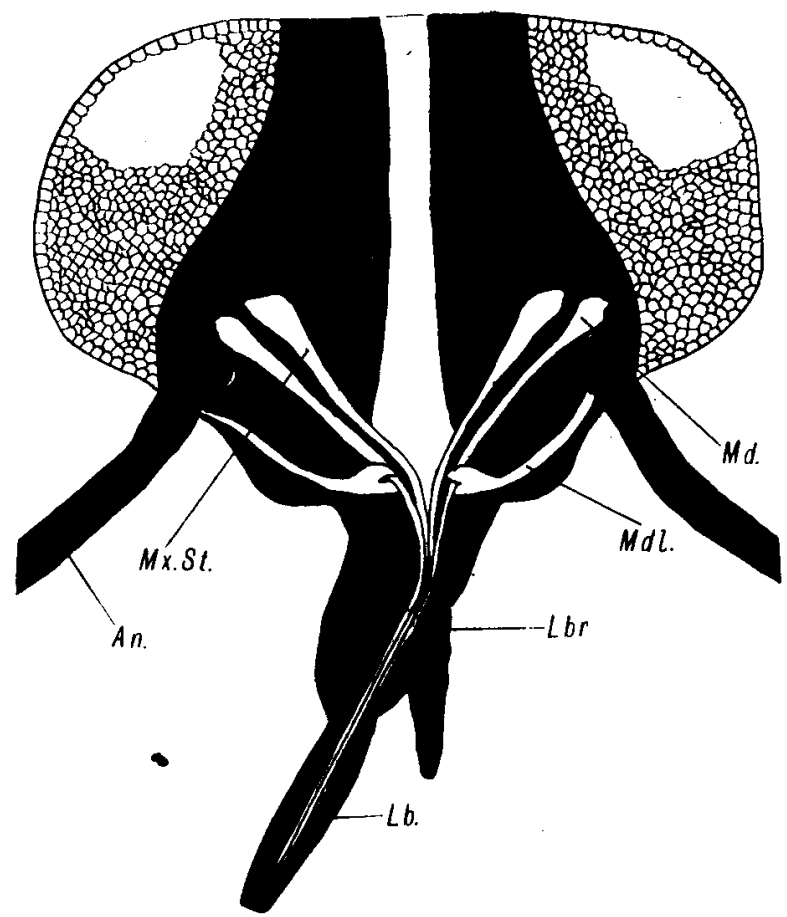

Fig. 2. Semi-diagrammatic drawing of the head of Lygus pabulinus showing mouth parts.

Attempts were made under the binocular microscope to pierce the leaf with the mouth-parts of various species after they had been removed from the head so that there was no possibility of any salivary juices being injected: this was not very satisfactory owing to the extreme fineness of the stylets, but in a few instances perforation was effected but with no visible results, the stylets apparently being too minute to kill more than one or two cells by laceration. As regards the possibility of the loss of sap by sucking causing the damage, if this were so it would of necessity follow that all the species of Capsids and indeed any sucking insect should produce similar harmful results. 


\section{Damage to Plant Tissue from Capsid Bugs}

Taking all these facts into consideration, it will be seen that mechanical injury alone is not sufficient to account for such serious damage.

Turning now to the second possible explanation, that of injection of bacteria with the salivary juices, the following experiments were made to decide this point:

Very thin microtome sections of the salivary glands of Plesiocoris rugicollis and one or two other apple feeding bugs were cut in order to verify if possible, the presence of bacteria in the glands and ducts; the sections were stained with various bacterial stains, such as Victoria Blue, Carbol Fuchsin, Gram's Stain etc., but in no case were there any indications of bacteria. Sections were also cut of the damaged portions of apple and willow leaves and stained with various bacterial stains as above, in order to trace bacteria in the cells. Although some of the cells presented a slightly granular appearance, this was found to be due to the presence of the tannin and no bacteria could be discovered. Apple leaves badly damaged by $P$. rugicollis were then taken and ground up with sterile sand in a mortar under sterile conditions with the addition of a little sterile water, the resulting extract was allowed to stand and the clear red fluid drawn off, it was then injected with a sterile hypodermic syringe into undamaged apple and willow leaves. A solution of damaged willow leaf was made under similar conditions and also injected into apple and willow leaves.

The inoculations made were as follows:

(1) Inoculation of apple leaf with sterile water control.

(2) Inoculation of apple leaf with extract of damaged apple leaf.

(3) Inoculation of apple leaf with extract as in (2) but boiled.

(4) Inoculation of apple leaf with a similar extract of willow leaves damaged by the same insect.

(5) Inoculation of apple leaf extract as in (4) but boiled.

A certain amount of damage was produced in each case, very slightly more marked in (2) and (4) than in the others. Five precisely similar injections were then made into willow leaves, these gave negative results, only such cells as actually came into contact with the hypodermic needle apparently being affected.

Bacterial cultures were then made from the damaged leaves as follows. The leaves were ground up as before with sterile sand and sterile water under sterile conditions and a drop of the resulting fluid was added to 10 c.c. of sterile water and plated out on various media, Turnip Agar + 4, Potato Mush Agar, Beef Agar, etc., after five days many small round colonies were observed, these were plated out until 
a pure culture of a bright chrome-red organism was obtained. A number of the harmless apple-feeding Capsids in a starved condition were then introduced into a petri dish containing the above culture; after they had all been observed to insert their stylets into the medium and to be well plastered with the colonies, they were transferred to a fresh young apple shoot and allowed to feed, no damage resulted. Suspensions were then made of the colonies and injected by means of a sterile syringe as follows into both apple and willow leaves:

(1) Sterile water control.

(2) Suspension of living bacteria.

(3) Suspension of dead bacteria (boiled).

A larger area of damage was caused by (2) and (3) than by the control, there presumably being a toxin present due to the presence of the bacteria in the injection, but as the damage caused by (3) was

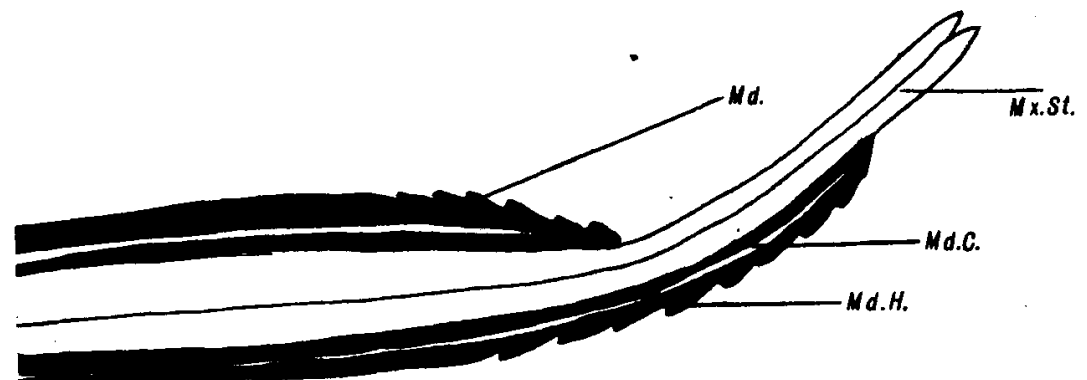

Fig. 3. Mandibles and maxillae of Lygus pabulinus. Drawn with the camera lucida, under the $\frac{1}{12}$ oil immersion, ocular 4.

precisely similar to that caused by (2), it cannot be taken as evidence that bacteria are the cause of the injury under investigation.

Inoculations were then made with a number of common bacterial saprophytes, including the red organism already mentioned, in order to find out if any of them would continue to live saprophytically in the plant tissue if entrance were made for them, either artificially by the needle or by the Capsid's stylets, and if so, whether they would produce damage similar to that known to follow the feeding of $P$. rugicollis.

The following inoculations were made into apple leaf:

(1) Suspensions of the red bacteria isolated from the damaged apple leaf.

(2) The same with dead bacteria.

(3) Suspension of Bacillus mesentericus.

(4) Suspension as in (3) but boiled. 
(5) Suspension of Bacillus vulgaris.

(6) Suspension as in (5) but boiled.

(7) Suspension of Bacillus subtilis.

(8) Suspension as in (7) but boiled.

(9) Suspension of Bacillus mycoides.

(10) Suspension as in (9) but boiled.

These inoculations were also made into willow leaves. In each case only slight damage was caused, in no way comparable to that produced by the Capsid.

The foregoing experiments seem to prove conclusively that bacteria play no part in producing the damage resulting from the feeding of the bug. The fact that the insects from the moment of hatching produce the same damage as the adults, also militates very strongly against the theory of bacterial infection as it would necessitate the bacteria passing on from generation to generation and also their having to pass the winter in the egg. The chrome-red colonies of bacteria which were isolated from the damaged apple leaf were presumably merely living on the surface and had no connection with either insect or damage.

There is left now the third possibility, i.e. that the salivary secretions injected into the tissue have a toxic effect. There are known to be two ducts (Awati(4)) down one of which there passes the salivary juices while up the other passes the plant sap, presumably mixed with some saliva. The saliva is injected under pressure by means of the very powerful pump situated in the head of the insect. After the leaf has been punctured and the insect's stylets withdrawn, a drop of fluid exudes from the hole and slowly grows in size as the cells below are killed and give up their contents. This is in marked contrast to the prick with a sterile needle or the puncture made by the harmless bugs where no drop of fluid exudes. The theory of harmful salivary injection is certainly the most probable of the three possible explanations, and further observations seem to bear this out.

The salivary glands of Capsids in general consist of a paired bilobed gland (see Fig. 4) situated in the meta-thorax one on each side, from the centre of this runs a long tube with apparently glandular walls, up to the neck where it doubles back again, ending near the gland proper in a very thin walled vesicle or reservoir which is not secretory; a second tube arises at the same point as the first and runs straight to the neck where it connects with the pump. Attempts were made to discover if any morphological difference existed between the salivary glands of $P$. rugicollis and those of other apple-feeding Capsids. 
The insects were fixed in Carnoy's fluid (second formula) mostly in the early stages, or after a moult, before the chitin was hard. In spite of these precautions great difficulty was experienced in getting good penetration of the fixing fluid, and it was found necessary to detach the legs or make a small hole in the abdomen for the fixative to gain an entrance. Great care was necessary in embedding in the wax, as too long or too short a time caused the chitin to become too hard and brittle to cut. It was thought possible that the glands of $P$. rugicollis might show some extra secretory cells or that the reservoir itself might prove secretory, but no histological peculiarity was apparent, the salivary apparatus being almost identical in the various species examined, the reservoirs showing as thin collapsed vesicles.

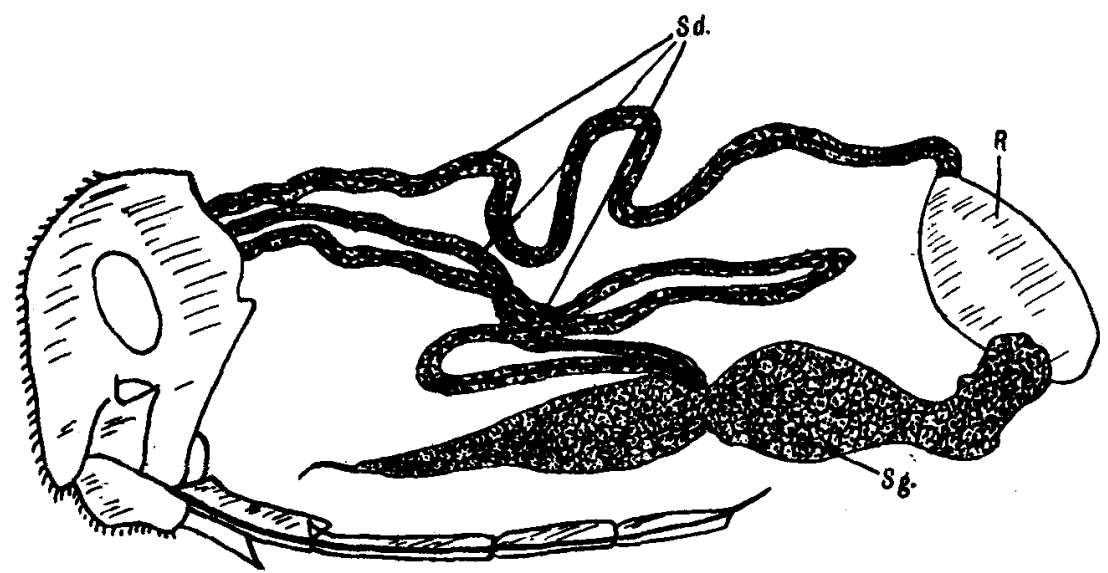

Fig. 4. Semi-diagrammatic drawing of the salivary apparatus of Plesiocoris rugicollis. One side only.

The fact of there being no apparent histological differences in the salivary glands of the harmless and harmful bugs does not tell directly against the theory of a toxic secretion, and all other experiments seem to point to this being the true explanation. That the damage to the cells spreads after the bug has moved to another spot, and that the mesophyll dies before the epidermis (except of course where there is a drop of sap and saliva lying on the surface of the leaf) are facts which tell very strongly in favour of this theory. Fig. 4 is a semi-diagrammatic representation of the salivary apparatus of $P$. rugicollis.

Injections were made with various dilute poisons into apple and willow leaf in order to reproduce if possible the damage caused by the bug. 
(1) Dilute ammonia.

(2) Chloroform.

(3) Various dilute acids, such as hydrochloric, etc.

(4) Xylol.

In each case the leaf assumed a spotted and patched appearance, very similar to the effect produced by the Capsid, and the leaves were put back in their development to a similar extent, while if pricked with the fluid so that more than 25 per cent. of the area of the leaf was affected, the leaves died. The characteristic red spots appeared on the apple leaves and the clear patches of dead cells appeared on the willow.

The same injections were made into the apple fruit itself, the chief result being the extraordinary retarding effect on the growth of the apple; after a week or ten days the control fruit was twice to three times the size of the pricked fruit, and in many cases the inoculated specimens fell off after ten days or a fortnight.

Further experiments were made to prove conclusively if possible the harmful effects of the salivary juices of Plesiocoris rugicollis. A number of the harmful Capsid bugs were ground up in a sterile mortar with a single drop of sterile water and the resulting fluid injected into apple and willow leaves. At the same time and into the same trees, a similar fluid, made from harmless apple Capsids, was also injected, in each case with a sterile water control. This experiment was unsatisfactory, no conclusive results could be drawn from it. A certain amount of damage was done in each case, possibly slightly more in the case of the extract of the harmful bug than in the other, but it seems probable that the harmful substance in the salivary glands was so diluted or neutralised by the other juices of the body or by the sterile water as to lose its toxic effect.

The same experiment was repeated, this time without the sterile water but again with unsatisfactory results.

Finally the whole salivary apparatus was removed from harmful and harmless bugs and pricked into the leaf tissue. This was definitely satisfactory, as the glands of the harmful bug $(P$. rugicollis $)$ were very much more toxic than those of the harmless bug ( $P$. ambiguus) which had little or no effect. The salivary apparatus of the injurious insect was placed on a young apple leaf and a small prick with a sterile needle made through it into the tissue beneath. In an hour or two the cells underlying the gland were all killed and by the next morning 50 per cent. of the leaf was dead: a similar prick made through the glands of a harmless Capsid under similar circumstances produced no effect whatever. 
As has been mentioned already in this paper the damage to the apple fruit itself is very considerable, owing to the fact that the growth of the apple is almost entirely stopped by the death of the cells of the exterior; in cases where one side only is punctured by the bug, the other side of the apple continues to grow to a certain extent thus causing a greatly distorted fruit.

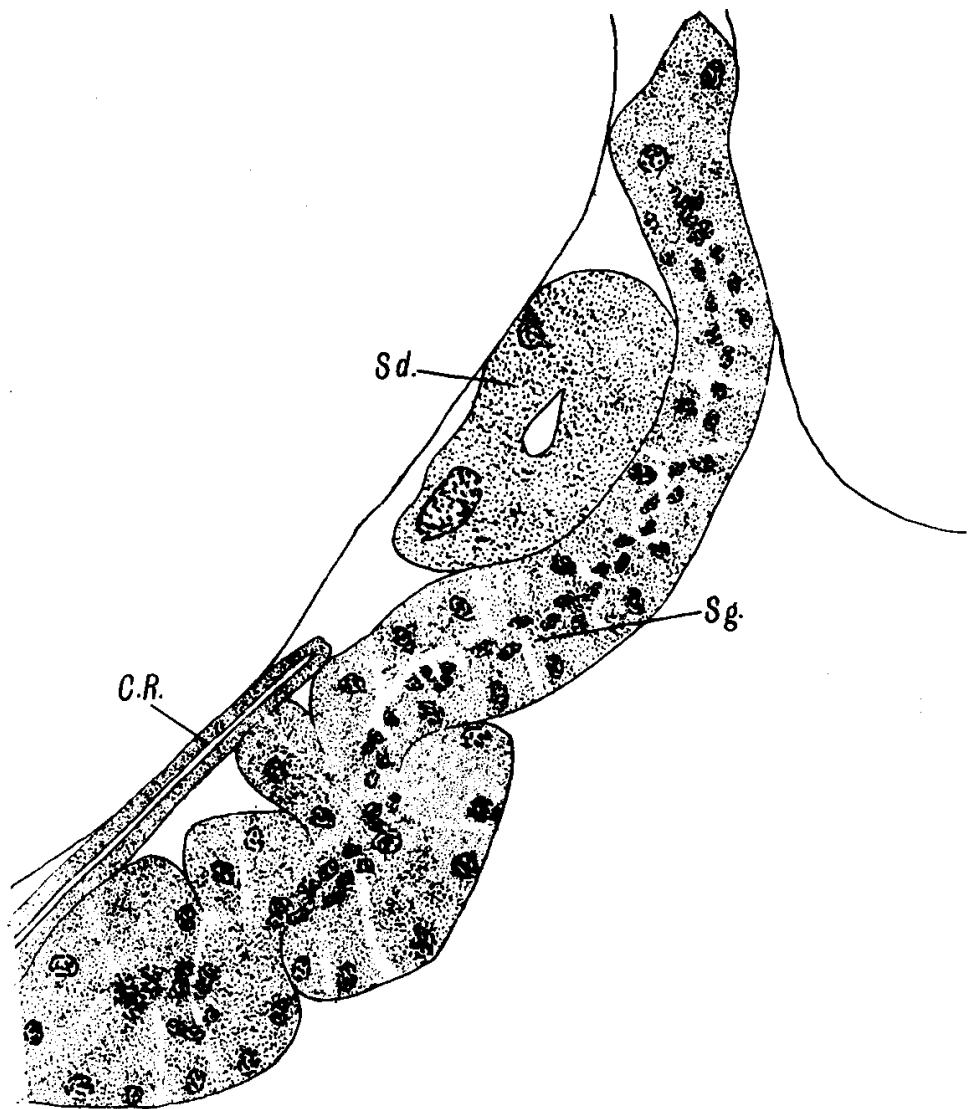

Fig. 5. Section of the salivary gland of Lygus pabulinus, $4 \mu$ thick, $\frac{1}{1}$ th oil immeroion, ocular 4.

When an apple is punctured by the harmful bug, a drop of fluid exudes from the puncture and gradually increases in size, the cells surrounding it are all killed and a corky layer is formed. To investigate this phenomenon further a number of slices of potato were put in damp chambers (Petri dishes lined with wet filter paper) and harmful and harmless bugs introduced. 
The object of using potato was to produce the same reaction as in the apple, but on a magnified scale. Plesiocoris rugicollis, Lygus pabulinus (a species harmful to potato foliage, etc.) and Psallus ambiguus were the species used. As soon as the bugs were introduced into the petri dishes they commenced to feed vigorously on the potato slices. From the punctures made by $P$. rugicollis and $L$. pabulinus a small drop of clear fluid exudes, this drop continues to increase in size for two or three hours, by which time it has attained a maximum diameter of about 3 millimetres and become greenish in colour. This drop finally dries up and leaves a large area of blackened dead cells. When the harmless bug sucks the potato no damage is caused to the tissues nor is there any exudation of fluid.

The explanation of the appearance of the drop appears to be that the salivary injection continues to work its way in the tissue till its toxic powers are exhausted, and as each coll is killed its turgidity is lost and its contents exude, forming the large drop as described. It is a striking fact that this exudation should only occur in the case of the harmful bug.

Plate III, fig. 2 is a photograph of potato slices which have been fed upon by the bugs: A and B, by $L$. pabulinus; C, by $P$. rugicollis; and $\mathrm{D}$, by $P$. ambiguus. In $\mathrm{A}, \mathrm{B}$ and $\mathrm{C}$, will be seen the blackened areas of dead cells round each puncture while in $\mathrm{D}$, although fed upon to a similar extent by Psallus ambiguus, there are no harmful results whatever.

The following detailed observations were made of the feeding of $P$. rugicollis and L. pabulinus upon potato.

P. rugicollis. Times after removal of stylets from puncture. Size of drop exuded, in millimetres.

\begin{tabular}{|c|c|c|c|c|c|c|c|}
\hline & 1 min. & 20 mins. & $1 \mathrm{hr}$. & $2 \mathrm{hrs}$. & $3 \mathrm{hrs}$. & $4 \mathrm{hrs.}$ & $12 \mathrm{hrs}$. \\
\hline (1) & $(t$ & $\left(\frac{1}{2}\right.$ & $\frac{3}{4}$ & $1 \frac{1}{2}$ & 2 & $2 \frac{1}{2}$ & $2 \frac{1}{2}$ \\
\hline (2) & 1 & $\frac{1}{2}$ & 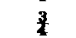 & $1-1 \frac{1}{2}$ & 2 & 2 & 2 \\
\hline (3) & 1 & 1 & $\frac{1}{2}$ & 1 & $1-1 \frac{1}{2}$ & 2 & 2 \\
\hline $\begin{array}{c}\text { Lygus } \\
\text { pabulinus }\end{array}$ & 采 & . & & & & & \\
\hline (1) & 1 & $5 \mid \frac{1}{2}$ & $1 \frac{1}{2}$ & 2 & 3 & 4 & 4 \\
\hline (2) & 0 & $\frac{1}{2}$ & 1 & 2 & 3 & $2-3$ & 3 \\
\hline (3) & t & $t$ & $\frac{1}{2}$ & $1 \frac{1}{2}$ & 2 & 2 & 2 \\
\hline (4) & $t$ & $\frac{1}{8}$ & $1-2$ & $2 \frac{1}{2}$ & 3 & $3 \frac{1}{2}$ & $3 \frac{1}{2}$ \\
\hline (5) & $t$ & $i$ & 1 & $1 \frac{1}{12}-2$ & 3 & 4 & 4 \\
\hline
\end{tabular}

A drop of this exudation was placed upon a young apple shoot; it was found to be decidedly toxic for after a few days the shoot died. 
A control experiment of pure potato sap alone had no ill effect upon the spple leaf although left in a damp chamber with the drop of sap in situ for several days, thus showing that some toxin had been added to the potato sap and that some chemical change had taken place, this latter as indicated by the change in colour after exposure to the air.

The salivary glands were then taken out of the following species, $P$. rugicollis, L. pabulinus and Psallus ambiguus, and placed each on the surface of a slice of potato; in the first two cases a large quantity of fluid was produced which gradually oozed out as before, and a large patch of tissue was killed; in the third case there was no effect at all. These drops of fluid were picked up with a capillary pipette and found to be toxic to apple leaves though not apparently to fresh slices of potato.

This seems fairly conclusive evidence that a harmful substance is injected by the bug and that it must be looked for in the salivary glands.

Observations were made of $P$. ambiguus in the act of feeding. Before the stylets are inserted into the tissue the proboscis is held upwards and a large drop of saliva gathers at the end, the proboscis is then lowered and the stylets forced into the tissue through the drop of saliva deposited on the leaf. After the insect has been feeding for some time the surface of the leaf is dotted over with these drops of saliva, these eventually dry up and leave no mark or visible after effect. If these drops are picked up with a capillary pipette and injected into the leaf no damage results, which is in marked contrast with the effect of the drop exuding from the puncture made by $\boldsymbol{P}$. rugicollis which kills the cells underlying it. There appears to be a slight difference in the method of feeding of these two bugs, whereas $P$. ambiguus secretes the saliva and pumps it out before piercing the leaf, $P$. rugicollis inserts the stylets first and then pumps in the saliva, the latter method certainly seems the most effective and it is difficult to account for the deposition of saliva outside the leaf unless this particular species is in the habit of producing greater quantities of the secretion than $P$. rugicollis, and pumps it into the leaf as well.

Sections were cut of tissue, fixed immediately after puncturing by the bug, also of tissue punctured by $\boldsymbol{P}$. ambiguus; these sections did not prove very successful, but punctures were discovered which penetrated some distance and showed laceration of one or two cells.

It is difficult to say how harmless bugs such as Orthotylus marginatus and $P$. ambiguus procure their food if their salivary injection does not kill the cells as it seems impossible that the contents of the one or two cells actually lacerated by the stylets should suffice for their needs; 
also, if the cells are killed, the characteristic red brown colour should be formed as it invariably is on the death of cells in apple tissue. It was thought possible that Psallus ambigurs injected some substance which prevented the formation of the tannin material in apple tissue, but although injections were made with various substances to try and produce this effect, e.g. acids of varying strength, etc., these attempts were unsuccessful, and almost invariably resulted in the formation of the red spots and patches except in the case of strong tannic acid which produced a hole surrounded by a pale margin.

A certain species of $J$ assid bug found feeding on horse chestnut and producing white spots thereon, was transferred to apple on which it produced similar white spots; apparently these cells were not dead or else, as suggested above, some substance was injected which prevented the formation of the red pigment. Lefroy and Horne (6), in their paper upon the effects produced on plants by sucking insects, put forward the theory that these white patches consist of cells filled with air. White spots are characteristic of the feeding of Jassid bugs, each plant damaged by them responding in a similar manner, at any rate in those cases of which the writer has personal knowledge, i.e. apple, pear, chestnut, and potato.

An interesting parallel case to that of the Capsids is found in the apple-feeding aphids, Aphis pomi, and Aphis sorbi; one of these has little effect upon the foliage while the other ( $A$ phis sorbi) causes curling of the leaves and the formation of a very bright pink pigment which is visible on the trees from a considerable distance, and which gives to the Aphis its name of Rosy Apple Aphis. Sections through this rosy material present an appearance exactly similar to that of sections through tissue damaged by $P$. rugicollis, i.e. dead cells filled with a granular material the only difference being in the colour of the pigment.

Experiments were then made with another species of Capsid known to be harmful to other plants, this was Lygus pabulinus, already mentioned in connection with the experiments upon potato; it is a very common insect and does considerable damage to the foliage of currant bushes, and produces the "shot hole" effect on potato plants. A number of these bugs were taken at a very young stage and "sleeved" upon apple trees, they took very rapidly to this new food and produced on apple and willow injury absolutely identical with that produced by $\boldsymbol{P}$. rugicollis; the change of food plant seemed to have no ill effect on the bugs, and they mostly became adults, very few dying.

Extracts were made of the salivary glands of this insect and injected into apple and willow, causing the same effect as that produced by the 
extract of Plesiocoris rugicollis. It seems fairly certain that a Capsid that produces damage to one plant produces damage to every plant upon which it feeds, although this damage varies slightly according to the reaction of the plant juices to the saliva. No case was found by the writer of a Capsid that was harmful to one plant being harmless to another, and conversely the harmless apple bugs, when induced to feed upon willow, were harmless to that also.

Lygus pabulinus was found feeding upon many different plants and trees, as shown in the following list; the effect produced in each case is given.

Red Currant. Reddish white patches and puckerings of leavas. Fruit untouched.

Black Currant. Whitish patches on leaves. Fruit untouched.

Pear. Black spotting of fruit and leaves.

Apple. Red spots and patches.

Plum. Red spots and patches.

Gooseberry. Reddish white patches on leaves. Fruit untouched.

Bindweed. Clear patches of dead cells. Similar to damage to willow.

Dock. Red spots.

Artichoke. Whitish patches with crinkling.

Potato. Brown spots. "Shot Hole" effect.

Willow. Clear patches of dead cells. Compare Bindweed.

This listwould apply equally well to the effects produced by $P$. rugicollis.

In all the above instances $L$. pabulinus was found feeding under natural conditions except in the case of the apple where they were "sleeved" on the tree. A number of young specimens of L. pabulinus were placed on small apple trees growing near some currant bushes without any measures being taken to prevent their escape; they remained upon the apple trees several days, causing a certain amount of damage, and then migrated to the currant bushes. It seems probable that if these specimens had been newly hatched they would have stayed upon the apple trees as it is quite easy to rear them under controlled conditions upon apple from early stages to adults.

An American worker, C. R. Crosby (7), records two species of Capsids, Heterocordylus malinus and Lygidea mendax, as living upon apples in America, and describes and figures injury exactly similar to that produced by Plesiocoris rugicollis and Lygus pabulinus, the two species more particularly dealt with in this paper.

An interesting point arises as to why $P$. rugicollis should have changed its food plant from willow and alder to apple, and if this species could do so why should not L. pabulinus do the same? It will be seen from the table of food plants that it has already a varied diet, it can also be 
easily reared upon apple as shown, so that it would not be altogether surprising if another pest were added to the already very long list of those attacking and injuring apple trees,

An attempt was made to find out the nature (acidity or alkalinity) of the salivary juices of various harmless and harmful bugs. Some specimens of $L$. pabulinus and $P$. rugicollis and Psallus ambiguus were starved for 24 hours and then introduced into a petri dish containing red and blue litmus paper soaked in sugar solution. The bugs would not as a rule insert their stylets more than once; the result of the insertion was to leave a brown spot on both red and blue litmus paper.

\section{SUMMARY.}

There are several species of Capsid bugs which normally feed on the leaves and fruit of apple trees but only one causes any damage, i.e. Plesiocoris rugicollis. This species produces the death of the tissue surrounding each puncture in the leaves made in feeding and on the fruit produces great distortion and "russeting."

There are three possible explanations of this damage:

(1) A purely mechanical injury produced by the insect's stylets in process of sucking.

(2) The possibility of the bug acting as a "carrier" of bacteria and by injecting these into the plant along with the saliva so sets up a pathological state.

(3) The injection of some secretion from the salivary glands which has a violently toxic effect on the plant tissue.

It was found impossible to reproduce by mechanical means the injury resulting from the feeding of $P$. rugicollis, also the fact that the other species of Capsid bug feed in a similar manner and produce no injury militates strongly against the theory of mechanical injury only.

As regards the second theory, no bacteria could be discovered in micratome sections of either damaged plant tissue or the salivary glands of the bug, and all attempts to reproduce the damage by means of bacteria failed.

The third theory was proved to be the correct explanation by several experiments and observations.

Experiments were made to try and reproduce the bug injury with various dilute poisons; in most cases a very similar appearance was produced in the foliage, but the attempts were unsuccessful in the fruit itself with the exception of the very great retarding effect in the growth of the fruit, which is one of the results of the bug injury.

By feeding the bugs on slices of potato instead of apple the same 
THE ANNALS OF APPLIED BIOLOGY. VOL. VII, NO. 1

PLATE III

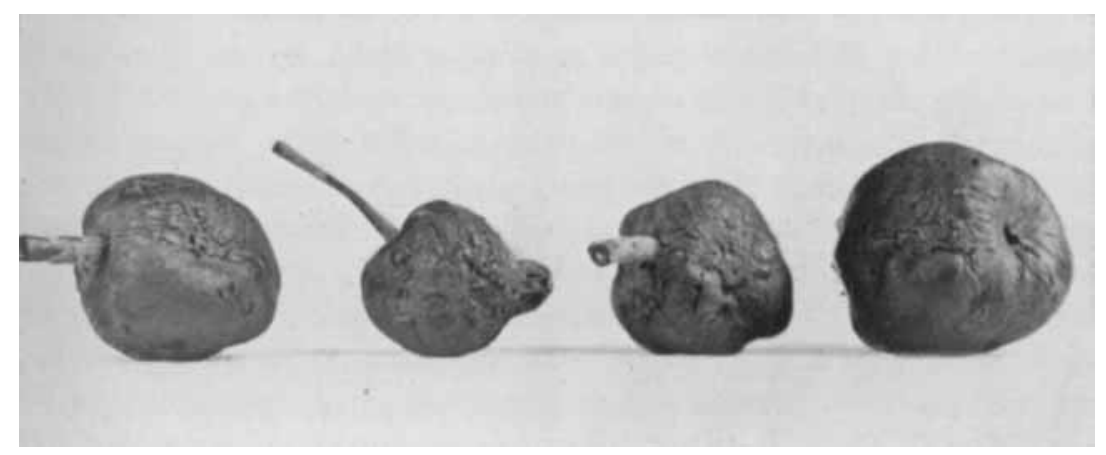

Fig. 1.

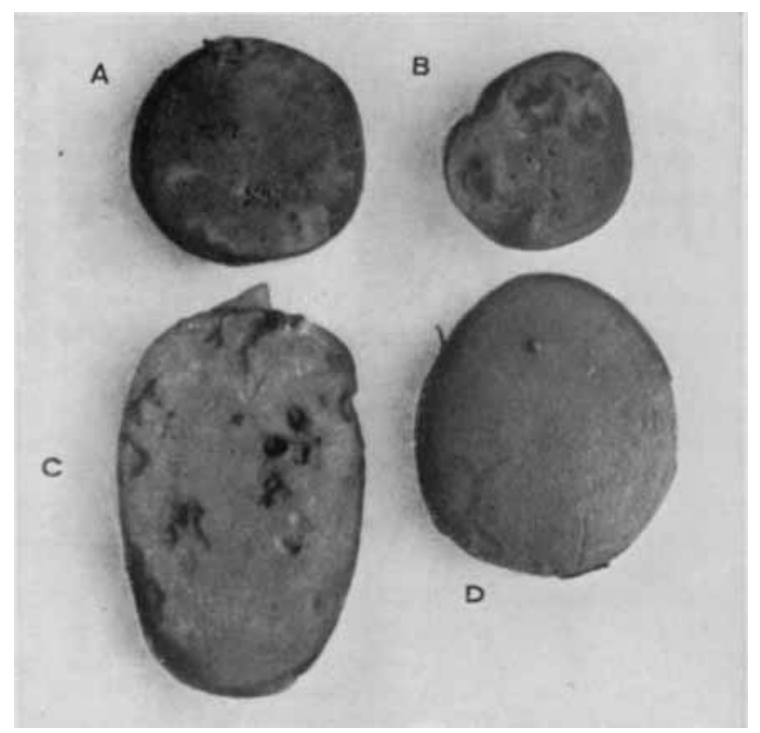

Fig. 2. 

effect was produced, but on a magnified scale. The salivary glands of $\boldsymbol{P}$. rugicollis and of Lygus pabulinus, a bug harmful to potato foliage, when placed on a freshly cut slice of potato in a petri dish, produced a violent reaction which killed much of the tissue surrounding the glands. The same experiment was carried out with the glands of one of the harmless apple-feeding bugs Psallus aimbiguus, these had no effect whatever on the potato. When the salivary glands of $P$. rugicollis were pricked into apple buds, the shoots were killed within 24 hours. The salivary glands of $P$. ambrigurs when similarly treated had no effect. Observations were made showing the rate of exudation of sap from the bug's puncture in the potato and these are given for $P$. rugicollis and Lygus pabulinus. A list of common plants and fruit trees with their various reactions to the feeding of harmful bugs is also given.

\section{BIBLIOGRAPHY.}

(1) Fryer, J. F. Preliminary note on the damage of apples by Capsid bugs. Annals of Applied Biology, I, No. 2, 1914.

(2) Petherpridar and Husain. A study of the Capsid bugs found on apple trees. Ibid., rv, No. 4, March, 1918.

(3) Collinge, Walter E. Remarks upon an apparently new apple pest. Journal of Economic Biology, June 1912, vII, Part 2.

(4) Awati, P. R. Mechanism of Suction in the Potato Capsid Bug, Lygus pabulinus. Proceedings of the Zoological Society of London, September, 1914.

(5) Staki, C. F. and Carsner, Eubanks. Obtaining Beet Leaf Hoppers Nonvirulent as to Curly Top. Journal of Agricultural Research, xIv, No. 9, Washington, D. C., August, 1918.

(6) Hornt, A. S. and Lerroy, H. M. Effects produced by Sucking Insects and Red Spider upon potato foliage. Annals of Applied Biology, I, Nos. 3 and 4, January, 1915.

(7) Crossy, C. R. The apple red bugs. Cornell University. Agricultural Experiment Station of the College of Agriculture, Bulletin 291, January, 1911.

\section{EXPLANATION OF PLATE III}

Fig. 1. Photograph of four apples, showing the typical damage produced by Plesiocoris rugicollis. Note the "scab" effect.

Fig. 2. Photograph of four slices of potato. A, B damaged by L. pabulinus, C by $P$.rugicollis and D fed upon by $P$ sallus ambiguus, but undamaged. In A, B, note the large punctures surrounded by dead and blackened tissue.

\section{EXPLANATION OF LETTERING.}

An. Antenna. C.R. Collapsed Reservoir. Lbr. Labrum. Lb. Labium. Md. Mandibles. Mdl. Mandibular lever. Md.C. Cavity of the mandibles. Md.H. Hooks of Mandibles. $M x . S t$. Maxillary Stylets. $R$. Reservoir. Sd. Salivary duct. Sg. Salivary gland. 
of the middle and hind legs of the male are hunched up, the femora ascending backwardly and the tibiae descending forwardly making a sharply acute angle with the femora. The head of the male extends forward above the level of the scutellum. The ventral side of the male's thorax rests upon the dorsal region of the female's abdomen, and the concave ventral surface of the male abdomen arches round the convex dorsal surface of the female's in such a manner that the hypopygium (the modified ninth abdominal segment) of the male with its claspers and intromittent organ extends under the extremity of the female abdomen and is closely applied to the latter for purposes of coition.

The act of pairing continues for about half an hour and even longer, and, if disturbed, the female endeavours to liberate itself by pressing

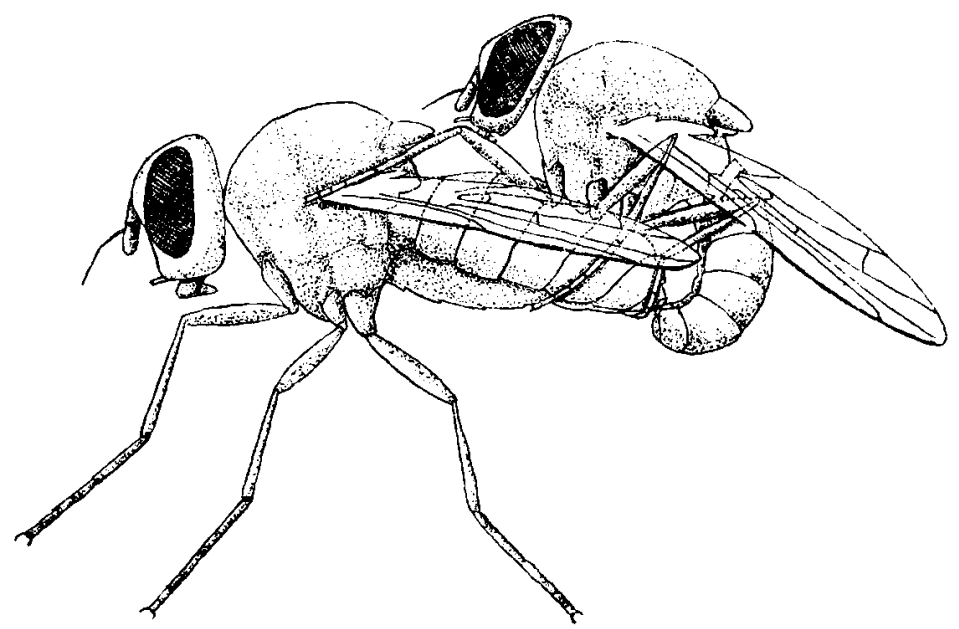

Fig. 1. Pegomyia hyoscyami in copulation. The investing bristles are omitted. $\times 12$.

with its posterior tarsi against the tarsi of the male, in its attempt to loosen them.

Martelli (1908) in his paper " Altre Notizie Dietologiche della Mosca delle Olive," p. 93, describes copulation in Dacus oleae. The position adopted by the male of this species is quite different from that of $P$. hyoscyami owing to the female's having a long, exserted ovipositor, which is general in the Trypetidae. In this case the anterior tarsi of the male embrace laterally the first abdominal segment of the female, while the others rest upon the ground.

Oviposition does not always take place immediately after copulation, and indeed all evidence points to the necessity of an interval of one or 
The disease was originally confused with another well-known and wide-spread disease of the tapped surface, viz. Black Thread or Black Line Canker the causal fungus of which is a species of Phytophthora, Mouldy Rot being considered a virulent form of this.

Further investigation however showed that Phytophthora sp. was nęver present in tissues affected by Mouldy Rot, species of Cepkalosporium, Fusarum, Sphaeronema are constantly present and occasionally several other saprophytic fungi and bacteria are to be found in the tissues.

The writers commenced their investigations of this disease in December 1918 and in March 1919 issued a preliminary note on the subject (First Malayan Report, 1919, Rubber Growers' Association).

The fact that a species of Sphaeronema had already been suggested as the causal fungus, determined us in working first on this fungus, especially as the other fungi present in the diseased tissue are common and well known saprophytes. Attempts to isolate the Sphaeronema by means of pycnidiospores in the usual ways all failed, chiefly owing to the fact that they are exuded in a sticky mass, almost impossible to separate into individuals, and foreign matter, spores etc. is held tenaciously. These spore masses refused to separate in liquefied nutrient agar, and frequently were killed at the temperature necessary to keep the agar in a liquid condition.

We then tried to isolate the fungus by picking out resting spores under the microscope, but the results were not encouraging. Finally. we decided to try the mycelium fairly deep in the tissues and this gave the best results in the shortest time. Experiments with inoculations of Cephalosporium and Fusarium on stripped surfaces gave always negative results.

\section{ISOLATION OF THE FUNGUS.}

Portions of old dry bark which had been affected with mouldy rot were used as the starting point in investigating this disease. A portion of bark 6 inches square was removed from a healthy tree and the underlying fresh tissue exposed. Inoculation was effected by scraping the old infected bark, mixing the scrapings with distilled water and applying with a soft brush.

At the same time the inner surface of the bark removed was inoculated similarly, cut into four portions 3 inches $\times 3$ inches and kept under observation in covered glass dishes.

In 48 hours all the inoculated surfaces had become discoloured, turning a dirty brown, and by the end of the fifth day the cells of the 
outer surfaces in all cases had been completely killed. Species of Cephalosporium, Fusarium, etc., were gradually covering the whole with white mycelium, and bacteria were completing the work of destruction. Portions of infected bark and wood were examined microscopically after 48 hours and again after six days. The mycelium had in places penetrated to a depth of $\frac{1}{10}-\frac{1}{8}$ inch, apparently penetrating most deeply along the medullary rays and then spreading laterally more slowly. Even in cells slmost filled with mycelium, the nucleus in some cases was still present and apparently unaffected after six days, but in most cases, of the cells attacked, the contents had disintegrated or entirely disappeared. In the bark, cells containing tannin were also attacked. A few characteristic fruits (pycnidia) had developed by the end of the fifth day and quite a large number in six days, the surface where these appeared having turned quite black.

A mass of spores just emerging from the apex of a pycnidium was carefully removed on sterilised needles, the operation being conducted with the aid of a high power lens; the moulds present, Cephalosporium, Fusarium, etc., were as far as possible excluded and inoculations made on agar and on fresh bark sterilised outside with picro-formal, and then placed straight from the tree into sterilised tubes.

The bark showed the typical brown discolouration round the point of inoculation at the end of 24 hours.

One of these pieces of bark after six days growth was sterilised in $1 / 500$ corrosive sublimate solution, then washed with freshly boiled distilled water, and finally the upper (previously infected surface) being the original inner surface of the bark shaved off with a freshly sterilised chisel. A second shaving was then taken from the surface newly exposed, this presumably contained active pure mycelium, and in fact such proved to be the case, as on being brought into contact with clean bark fresh from the tree, the characteristic colouring was apparent in 18 hours, while the controls remain unaltered. In every case of successful inoculations, the attack spread with quite remarkable rapidity.

\section{CULTURES.}

Cultures were set up from spores removed from pycnidia produced on bark as above, on Prune agar, 2 per cent. virol agar, Quaker oat agar, agar made with infusion of rubber tree bark, and in every case pycnidia were produced in abundance in from five to nine days. Similar cultures on sterilised wood produced an abundance of pycnidia and also resting spores in from 10-15 days. Cultures on 2 per cent. cane sugar agar gave very 
good results. The growth on dolichos agar and on bean agar was much slower than on those previously mentioned, pycnidia however were produced even on these in about 20 days and a fair number of resting spores in the same time. In every case of inoculation of freshly exposed surfaces of bark or wood; infection was set up, and the disease rapidly spread over the entire surface exposed, more particularly when an excess of moisture was present.

In six cases portions of bark about six inches square were removed from the tree, and the exposed underlying surface inoculated with spores from pycnidia in water. When a considerable number of pycnidia had been produced on all these surfaces and they all showed the characteristic appearance of mouldy rot, jodelite was applied, and the next day a fresh portion of bark removed below, but in continuation with the first surface exposed. In every case the disease appeared on the fresh surface at the end of two days. Discolouration was apparent as a continuation from the previously affected part, the disease having spread downwards in the wood and innermost layers of bark. A similar experiment was carried out but fresh surfaces exposed laterally. The disease again spread to the freshly exposed surfaces.

Many of the cultures on artificial media produced considerable numbers of resting spores embedded in the media well below the surface. These large resting spores are produced in from 8-10 days after inoculation, and, being thick walled can withstand considerable desiccation without losing the power to germinate. Some infected material which could not be dealt with at once, was put aside in a desiccator so as to keep it as clean as possible, i.e. to prevent spores of various saprophytic fungi which are almost invariably present in the air from lodging on it. Six weeks later portions of the tissue were taken and infections obtained from resting spores, on stripped surfaces, thus proving that the extreme desiccation to which the spores had been subjected had not succeeded in killigg them. They are produced in abundance on the infected surface in dry weather, taking the place of the pycnidia. The third type of spores which so far we have only found in cultures in the laboratory, is very similar in size to the pycnidiospore and is cut off directly from the mycelium. Examination of infected cortical tissue in which the disease had been present 8-10 days showed that large numbers of globules of an oily or fatty nature were present. These varied much in size and were fairly evenly distributed throughout the tissue, which had been killed by the fungus.

Cortical tissue which had been affected for a considerable time con- 
tained these globules sometimes in great abundance, some of the cells being full of them. No trace of these could be seen in the cultures on artificial media, they are not present either in recently infected, or normal healthy cortex. Tissue which had been killed and partially destroyed by the Sphaeronema formed then a suitable nidus for bacteria which were present in abundance. One case of inoculation on a stripped surface which was kept under observation proved very interesting.

The surface was inoculated $27 / 11 / 18$ and six days later pycnidia appeared. In the meantime the mycelium had spread over the entire surface exposed (about 24 square inches).

Cultures were made from pycnidiospores and the surface was then left, i.e. no fungicide was applied.

By 28/12/18, approximately a month later, healing from the edges had made fair progress and a month later still the wound appeared to be in a fair way to recovery.

More cortex was removed 2/2/19 both above and below but in continuation with the part previously exposed, and in less than four days there was the usual appearance on these stripped surfaces showing that the disease was spreading. In eight days pycnidia appeared on these newly exposed surfaces and examination of portions of wood in sections from the original surface showed that the mycelium had penetrated $\frac{1 "}{8}$ and was then spreading slowly in a vertical direction.

Other cases similar to the above inoculated $5 / 12 / 18$, and treated with an antiseptic cover, but in which no further surfaces were exposed, have now almost completely healed over. The cortex shows no signs of disease (9/1/20) and there is every appearance of complete recovery. Regeneration from the sides will however give a very uneven surface to tap over.

During wet weather pycnidia are produced in abundance on the affected surfaces while resting spores are not at all common. In some cases where the disease proved most difficult to keep in check during a prolonged spell of dry weather, no pyenidia were produced, but immense numbers of resting spores were formed on the surface and some were also found embedded in the tissue several cells deep. Under those conditions it is probable that the resting spores provide an even surer means of distribution than the pycnidiospores and these as well as those in the tissue are equally dangerous so long as tapping is continued, the knife then being the chief agent in their distribution from tree to tree.

The pycnidiospores are quickly killed by desiccation but the resting spores can withstand this for quite a long time. 
DESCRIPTION OF THE FUNGUS.

The causative fungus is a species of Sphaeronema which belongs to the group Fungi Imperfecti.

The mycelium is dark coloured-brownish-the filaments are formed of cells varying much in length compared with the width, much branched, and under suitable conditions as regards moisture, etc. grows rapidly at the expense of the host. Normally the fruiting body, a pycnidium, is produced by the end of the fifth or sixth day after inoculation. These were produced in abundance in cultures in the laboratory in about the same period as on the trees attacked.

The pycnidium is quite characteristic and should always be looked for in supposed cases of "Mouldy Rot." A pocket lens of powers $\times 10$ diameters shows it up quite well. When mature it is a black, flaskshaped body $\cdot 12 \mathrm{~mm} .-\cdot 24 \mathrm{~mm}$. wide at the base and $\cdot 24 \mathrm{~mm} .-\cdot 9 \mathrm{~mm}$. long including the long narrow neck which is $\cdot 02 \mathrm{~mm} \cdot-\cdot 024 \mathrm{~mm}$. wide. The long neck has a distinctly striated appearance due to the presence of thicker portions in the form of strands. At the apex the strands split apart somewhat from the connective tissue (see $\mathrm{Pl}$. IV, figs. $a$ and $b$ ) facilitating the discharge of masses of pycnidiospores.

The pycnidia arise directly from masses of the dark coloured mycelium, which with the black pycnidia give the infected surface a black appearance; as the attack progresses this effect is accentuated. Pycnidia are, under favourable conditions produced in immense numbers, many hundreds being crowded together in quite a small area. The pycnidiospores are produced in the base of the pycnidium, and in a sticky matrix are gradually forced up and out of the neck, adhering when freshly exposed as a white, more or less globular, sticky mass, which rapidly turns brown when dried.

Eventually the mass is pushed over the side and remains sticking to the outside of the neck, being followed in a very short period24 hours or more-by a second mass. The masses of pycnidiospores are very quickly affected by desiccation. By the time the mass has turned dark brown, it may be quite a short time after expulsion from the pycnidia, they have lost all power of germination, hence a dry season helps greatly in controlling the disease while a wet one makes it more difficult. This has however proved not always to be the case, as in some cases immense numbers of resting spores are produced when pycnidia are altogether absent during a dry period. The individual pycnidiospores $2 \cdot 5$ microns $\times 4$ microns are slightly attenuated and rounded at the ends. When fresh they germinate almost immediately on a suitable medium, 
e.g. a fresh surface exposed by tapping. Besides these, two other kinds of spores are produced, one being a large, almost spherical, thick walled resting spore 10-20 microns in diameter (the great majority are 10-14 microns in diameter) produced at the ends of short lateral branches, especially on the mycelium at or near the surface (see Pl. IV, fig. c). Cases have been observed where these spores were produced on the mycelium embedded in the tissue several cells deep, and in the particular cases observed pycnidia were scanty or entirely absent (see Pl. V, fig. $a$ ).

From the experiments and field observations it would appear that with a high percentage of humidity pycnidia will usually be produced very quickly in large numbers, while under dry weather conditions the resting spores are produced sometimes in almost equal abundance. It follows of course that weather conditions cannot be relied on as an aid in checking or eradicating the disease.

Deep tapping undoubtedly aids in the thorough establishing of the fungus in the tissues since under those conditions penetration to the wood is quickly effected.

Much wounding during tapping also aids in a similar way.

\section{SYMPTOMS OF ATTACK.}

A freshly exposed surface of Hevea attacked by Sphaeronema turns darker in colour than normal in quite a short time ( 24 hours). In three days the infected surface rots, and various species of saprophytic fungi make their appearance on the dead tissue, the presence of these being indicated by the tell-tale more or less complete cover of white mycelium. This appearance is most noticeable one to two inches above the cut. Portions of the tapped cortex sink in, forming depressed patches of various sizes, which may in a bad case extend the whole length of the cut. The affected portion frequently turns quite black. Later, in neglected cases, the fungus penetrates the wood $\frac{1}{12}{ }^{\prime \prime}-\frac{1}{8}$, spreading vertically up and down the wood fibres.

The less serious cases where only small portions of the cortex become depressed resemble Black Line Canker, but usually pycnidia may be found, sometimes in considerable numbers.

The damage caused by this disease when neglected is probably greater than that due to any other bark disease of Hevea. The disease continues as long as tapping is continued and is easily spread from tree to tree by the knife.

Cortex destroyed by Sphaeronema is frequented by small Diptera 
and beetles both of which are liable to spread the disease especially by carrying the pycnidiospores which adhere to the legs and bodies.

Since the fungus quickly produces spores (5-6 days) once a tree is attacked and the initial attack overlooked, the spread of the disease is usually very rapid and whole tasks of 300-400 trees may be affected in the course of a week or fortnight.

The rapidity of spread and the short time in which it kills the tissues make this a most dangerous disease. A week may see the number of infections increased by hundreds.

The loss sustained by an estate affected by Mouldy Rot, unless efforts are at once made to obtain control and eradicate the pest, may be very great, as once it becomes fairly widespread tapping must be stopped for periods varying from $2-6$ months and this may have to be repeated after reopening if the diseass hows signs of reappearing. The distribution of remaining cortex after tapping also is bound to be serious if it continues for any length of time since a shortage of bark means loss of revenue.

When reopening trees after a period of rest due to Mouldy Rot the new cut if in the same section should be 4 inches below the old one; it is better to open up a new section and keep a sharp watch for any new infection which should be dealt with vigorously.

Two other species of Sphaeronema have been seen frequently by the writers growing as saprophytes on dead Hevea timber; one often appears on the cut surfaces of fresh timber during felling. These are always accompanied by hosts of small diptera which apparently find the sticky masses of pycnidiospores an attraction. Both these species produce fruit (pycnidia) viz. quickly, one of them usually in about three days or even less.

We are indebted to the Rubber Growers' Association for permission to publish the results of this work carried out on their behalf.

\section{REFERENCES.}

S'cond Malayan Report for 1917. Rubber Growers' Association, Agricultural Bulletin Federated Malay States, vi, No. 1, October, 1917.

lirist Malayan Report 1919. Rubber Growers' Association, Kuala Lumpur, F. M. S., March, 1919.

Third Malayan Report for 1919. Rubber Growers' Association, Kuala Lumpur, F. M. S., December, 1919. 


\section{DESCRIPTION OF PLATES}

\section{PLATE IV.}

Fig. (a) Pycnidium and mycelium of Sphaeronema ep. Note the mass of spores at the apex of the pyonidium. $x$ about 60.

Fig. (b) Apex of pycnidium showing spores and strands. $x$ about 190.

Fig. (c) Resting spores of Sphaeronema sp. These occurred commonly during a prolonged period of dry weather when no pycnidia were produced. $\times$ about 130 .

Fig. (d) Section of infected tissue showing pycnidia and resting spores on the outer surface. $x$ about 32 .

\section{PLATE V.}

Fig. (a) Section of infected cortex showing resting spores formed within the tissue. $x$ about 200.

Fig. (b) Section of wood showing the mycelium of the fungus in the cells. Nuclei are still present in some cases, the rest of the cell contents being destroyed. $x$ about 225.

Fig. (c) Resting spores produced on artificial medium (nutrient agar jelly) after 8 days. $\times$ about 100 .

Fig. (d) Myoelium in cells of diseased cortex. $\times$ sbout 200.

\section{PLATE VI.}

Fig. 1. Recently tapped surface (A) attacked by the disease.

The whitefelt-like masses of mycelium of saprophytic fungi, chiefly Cephalosporium, are irregularly distributed over the decayed surface. The real cause of the disease is more deeply seated and is spreading downwards keeping pace with the tapping. The cortex B-C had been treated with an antiseptic tar mixture several times. Portions of the exposed wood so treated (D) some considerable time after treatment showed irregular white patches. These were due to a granular deposit the result of some chemical action, of the disinfectant cover on the tiseues.

Figs. 2 and 3 illustrate the effect of mouldy rot on a freshly stripped surface. Two portions of cortex were stripped at the same time.

(a) Was inoculated with spores of Sphaeronema in distilled water, the spores being placed on the surface with a soft brush.

(b) Was not inoculated (control).

Fig. 2 shows the appearance 24 hours after inoculation.

Fig. 3 shows the appearance six days after inoculation.

Within six days the Sphaeronema had produced pycnidia. It will be noticed that on the infected surface, the corter is utterly destroyed down to the wood. Saprophytic fungi are present on the decayed tissue. $x$ about $t$.

\section{PLATE VII.}

Fig. 1. Tapped cortex of Hevea attacked by mouldy rot. The disease which started at A followed the tapping down to $B$ and is still continuing.

Fig. 2. Extension of the disease to new cuts. The disease had almost completely destroyed tne tapped surface A-B (over 3 feet). A new cut was then opened at $C$ on new portion, infection quickly followed because the disease was still carrying on all round in other trees. The new infection is as previously keeping pace with the tapping (C-D).

Note the large open wounds on the surface A-B, and C-D will show a repetition of this. When the new cut started at $C$ is finished, there will be no tappable cortex left below $4 \mathrm{ft}$. from the ground. 
THE ANNALS OF APPLIED BIOLOGY. VOL. VII, NO. 1

(a)

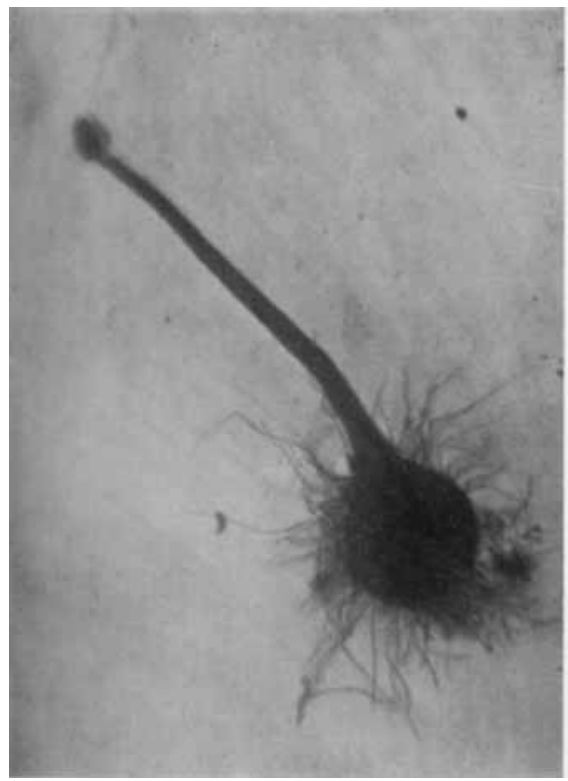

(c)

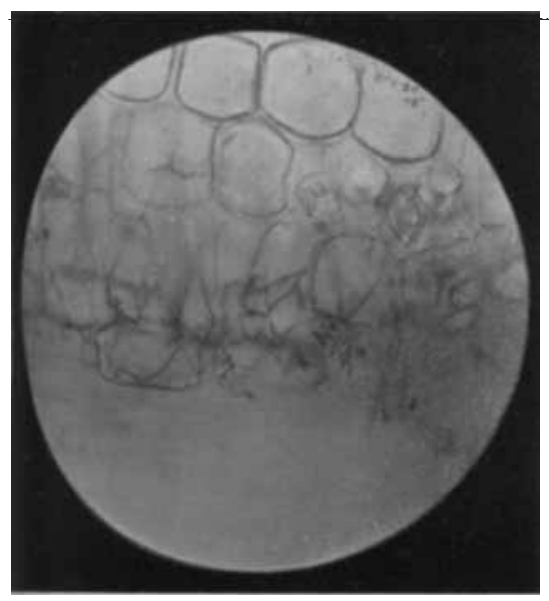

(b)

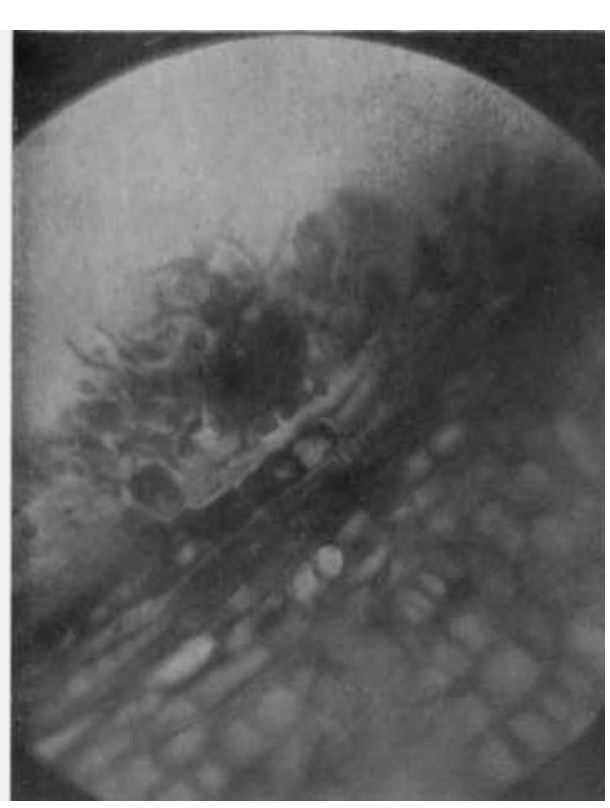

PLATE IV

(d)

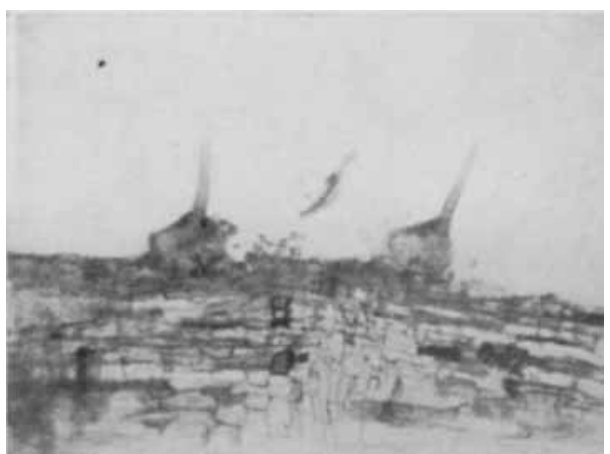

Sphaeronema sp. 
(a)

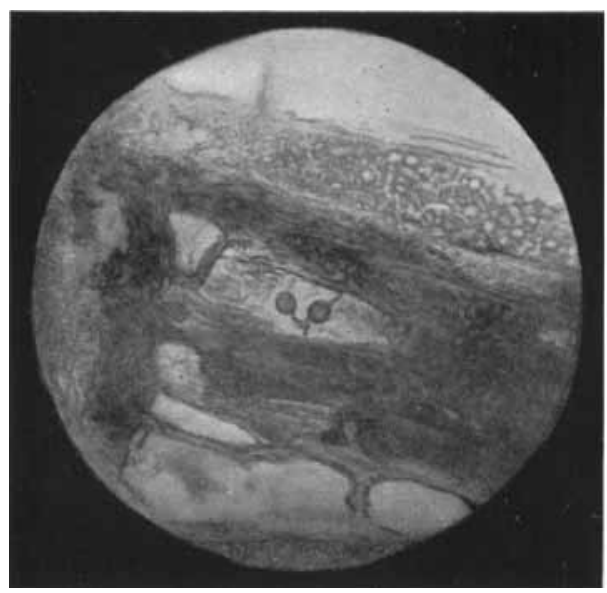

$(c)$

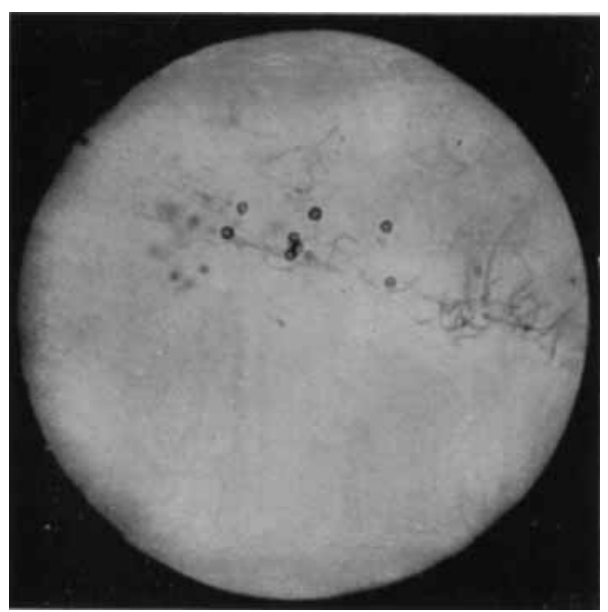

(b)

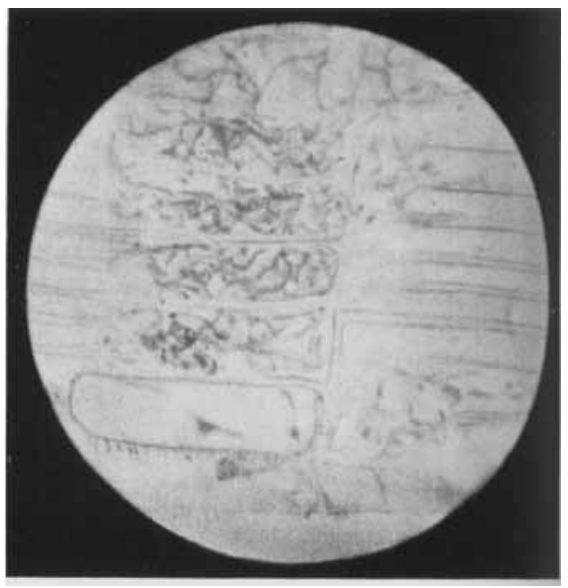

(d)

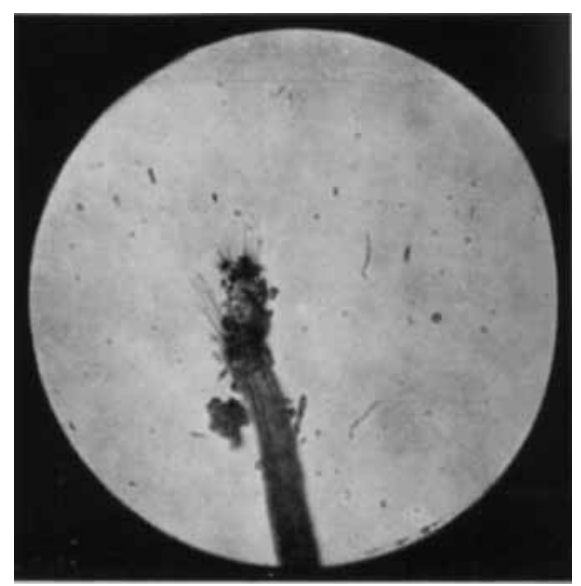

Sphaeronema sp. 
THE ANNALS OF APPLIED BIOLOGY. VOL. VII, NO. 1

PLATE VI

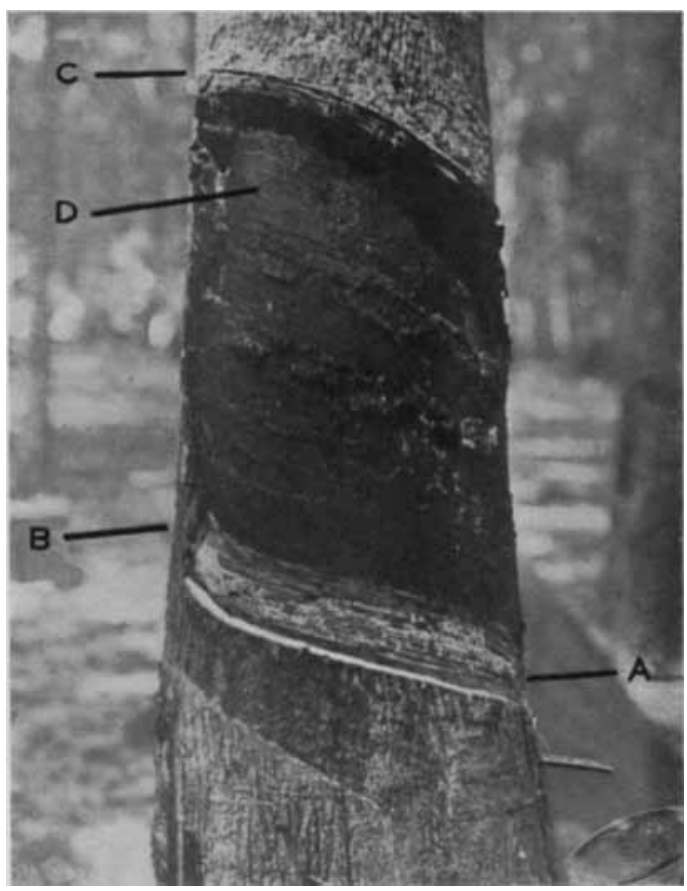

Fig. 1.

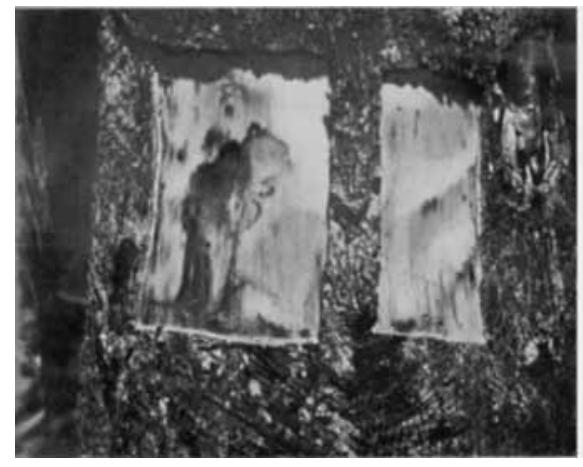

Fig. 2.

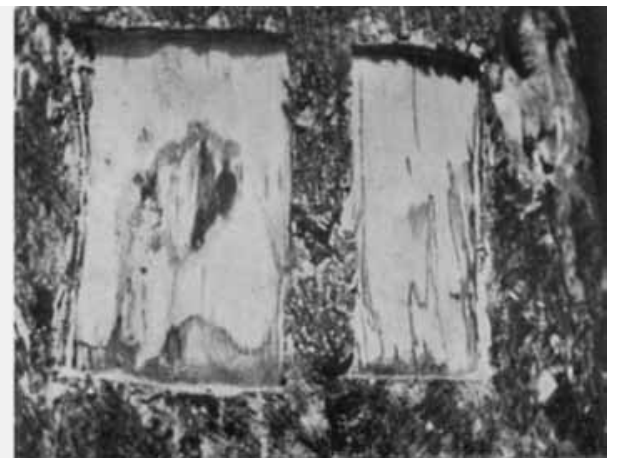

Fig. 3.

Sphaeronema sp. 


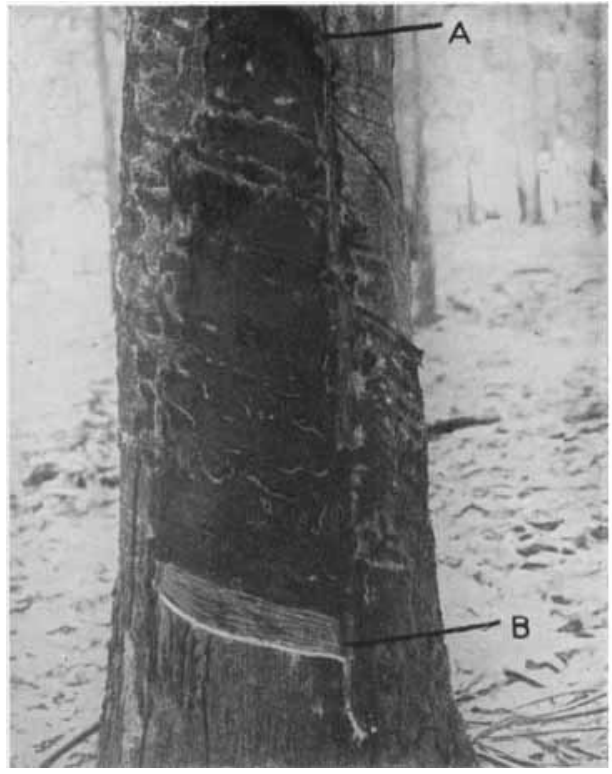

Fig. 1.

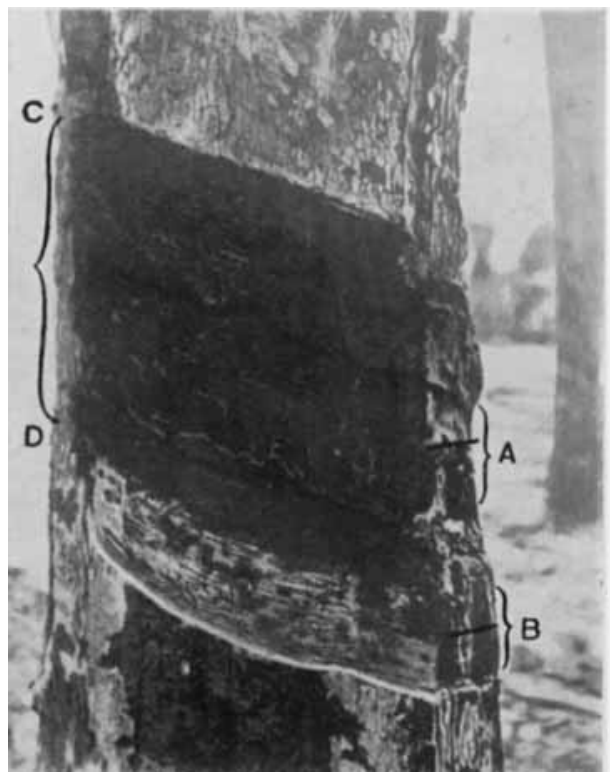

Fig. 3.

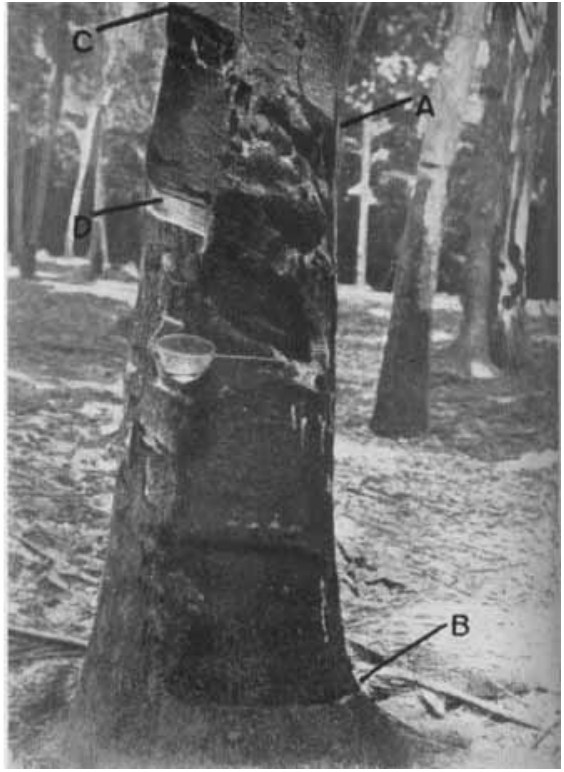

Fig. 2.

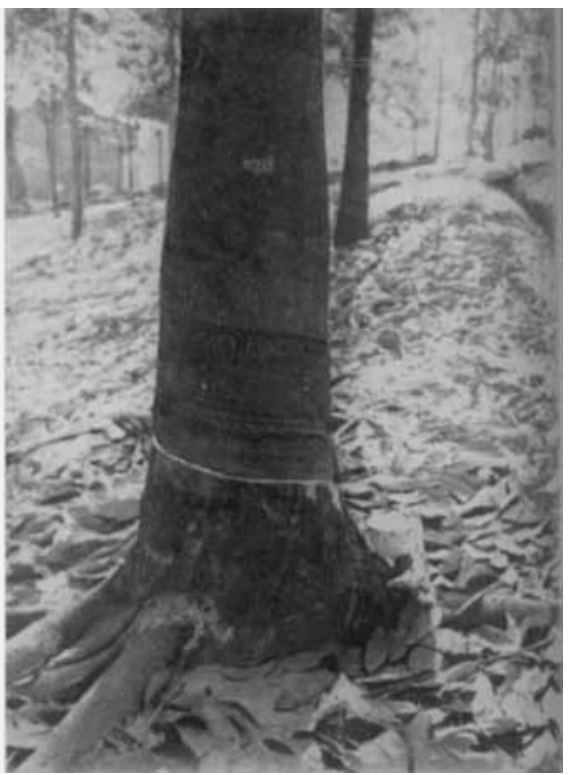

Fig. 4.

Sphaeronema sp. 
Fig. 3. In this specimen 20 inches of bark have been removed on the new cut. Fifteen inches of tapped surface is almost completely destroyed. The lowest five inches (B) shows the disease is still present in a virulent form.

Note the portion (A) where open wounds extend across the tapped surface.

The portion $\mathrm{C}-\mathrm{D}$ had been treated (too late) several times with an antiseptic cover.

The fungus is present in the wood and has already passed below the present cut, hence the disease will persist so long as tapping continues. The tree figured was one similar to that in fig. 2. The whole of one tapped surface (over $3 \mathrm{ft}$.) was completely ruined, and the second cut, which showed infection almost immediately after opening, is merely a repetition of what occurred on the previously tapped surface.

Fig. 4. Photograph showing tapped surface and tapping cut of a normal 15 year old Hevea tree unaffected by disease. 